\title{
Scenarios to explore the futures of the emerging technology of organic and large area electronics
}

\author{
Alireza Parandian • Arie Rip \\ Received: 14 January 2013 / Accepted: 2 May 2013 /Published online: 13 July 2013 \\ (C) The Author(s) 2013. This article is published with open access at Springerlink.com
}

\begin{abstract}
Emerging technologies pose challenges for futures research because of their uncertainties combined with promises. Actors are anticipating and acting strategically. Sociotechnical scenarios building on endogenous futures support and enlighten actors. Such scenarios contribute to "strategic intelligence" about the technologies and their embedding in society. Organic and large area electronics promise to substitute silicon-based technologies, but firms and potential users are reluctant to invest. Ways to break through this "waiting game" are the starting point for scenarios that were developed as in an input in strategy articulation workshops with different stakeholders and third parties. The scenarios are offered as they were an input in the workshops and are annotated to show the robustness of their construction. Recent developments confirm the diagnosis of the dynamics of the domain.
\end{abstract}

Keywords Scenarios · Endogenous futures · Waiting games · Organic and large area electronics · Strategy articulation workshops

\section{Introduction}

Emerging technologies, with their promises as well as uncertainties about eventual performance and embedding in society, pose specific challenges to futures research. Standard methods of technological forecasting and technology assessment cannot

\footnotetext{
A. Parandian $(\bowtie)$

Business Development, InnovationFab, P.O. Box 9716, 5602 LS

Eindhoven, The Netherlands

e-mail: alireza.parandian@innovationfab.com
}

\section{A. Rip}

Science, Technology and Policy Studies, University of Twente, P.O. Box 217, 7500 AE Enschede, The Netherlands

e-mail: a.rip@utwente.nl be applied, or only partially. At the same time, actors work with promises (and sometimes concerns), anticipate informally and more analytically, and base investment of resources on what are essentially bets on anticipated socioeconomic returns, as well as on possible actions of other actors [1]. In a sense, they are de facto futures researchers. When professional futures researchers offer their contribution, it is in a world full of anticipations and anticipatory action already, and they have to include this complexity [2].

As part of our approach of constructive technology assessment (CTA) of emerging technologies, we have addressed these challenges (cf. [3, 4]), in particular, by organizing strategy articulation workshops with different relevant actors (stakeholders and third parties), supported by sociotechnical scenarios reflecting the present situation and possible nearterm futures. We were inserting ourselves in the world, at least in workshops with different relevant actors, a microcosmos as it were, to help participants to anticipate and decide through better understanding of ongoing dynamics and insight into the repercussions of possible actions.

In this article, we report on the futures research we did for one of the domains we have worked in: organic and large area electronics (OLAE). This is an interesting domain in its own right, but as a case of an emerging technology, it serves to indicate how our approach can be more widely applicable. ${ }^{1}$ In our approach, we focus on what we call "endogenous futures" to emphasize how future developments are predicated on ongoing dynamics of development and the patterns in them which frame what actors perceive and how they act and interact. This shapes the future, without determining it. New interventions are played out against this background, and reactions and repercussions can be explored in those terms in scenarios, also basing ourselves on general insights

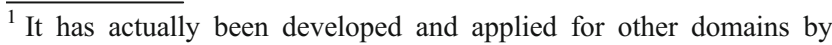
Robinson (cf. [2]), Parandian (cf. [3]), and Te Kulve (cf. [4]).
} 
in patterns and dynamics of technology development and innovation.

The "facts" of the present situation merge into the "fiction" of future developments (we use quotes because "facts" are never unambiguous and "fiction" has some factual basis). What is important is narrative plausibility in the sequence of events and interactions and the evolving patterns (cf. [5]). This is a general point about scenarios, but gets additional weight because our scenarios have to be plausible to the workshop participants with their different backgrounds, or better, be able to withstand their critical scrutiny. This applies to our starting point, the present situation and its dynamics, as well as to the controlled speculation (founded on our knowledge of the domain and its tensions and insights from technology and innovation studies) about repercussions of interventions that set the scenario story in motion.

These general remarks can be made more concrete by briefly introducing our case. The domain of OLAE is interesting because of its promise to replace silicon-based electronics, at least where performance requirements are not very high. But it is in an early stage of development, where openended promises dominate and new products are almost absent, or still tentative. This makes it important, as well as difficult, to explore futures of OLAE and its embedding in society.

The descriptive definitions of this new field of innovative opportunities have not yet stabilized and various adjectives are used to characterize it, e.g., flexible, organic, large area, plastic, and polymer electronics. The key novelty is that semiconducting devices are processed on novel, flexible substrates (for instance, plastic foils), with large area and low-cost production techniques of printing processes using highly functional materials. These developments are part of different traditional value chains and will have an impact on their linkages, including new business models for firms faced with these linkages. Product-market combinations, like flexible organic light-emitting diodes (OLED) light sources and displays, electronic labels for packaging, or cheap flexible solar cells integrated in various applications ranging from roof tiles to smart fabrics, offer functionalities which are not served by conventional rigid silicon-based electronics technologies. However, it is not obvious which directions to pursue. There is uncertainty about user interests and their priorities and, thus, also uncertainty which markets might be served and when technologies can eventually profit from large-scale commercialization. And there is uncertainty about regulatory aspects and customer and social acceptance. The net effect of these uncertainties is that the various business actors are reluctant to be the first to invest heavily in a new development. The situation can be characterized as a waiting game. Actors realize this, but cannot simply break through the waiting game [1]. We will detail this diagnosis in the next section when we discuss the dynamics of the development of OLAE and its possible embedding in society.
Actually, OLAE (or similar descriptors of the domain) is a generic concept which by now serves as a platform for a variety of applications in different industries and other domains, as well as a diffuse promise that mobilizes actors to pay attention to the domain. Application systems will adopt many different forms and sizes in specific industry settings, and their realization requires choices (sometimes difficult choices because of uncertainties about performance and about markets) with respect to different materials and production technologies.

All this implies that our futures study had to be based on the extensive exploration of different application settings and market and societal aspects, including interviews with actors active in different industries (like e-paper industry, OLED lighting industry, large area displays, organic photovoltaics, printed radio-frequency identification (RFID), and printable packaging solutions), and with some potential users. This will inform the analysis in this paper, although it will not be reported in detail.

Force fields in which various actors move could be identified, including tensions and dilemmas about strategic choices (including the choice whether to break through the waiting game, individually or collectively). Our empirical data emphasize developments in Europe, with occasional reference to what happens in North America and East Asia, because key actors (including the European Commission $[\mathrm{EC}])$ are Europe-based and key developments in the domain occur in Europe.

This is the basis for the analysis and diagnosis of what is at stake at the moment, the first step in our approach. We add identification of key questions that have to be addressed, sometimes formulated as dilemmas. These questions served to prime the interest of the participants (they were included in the preparatory material that was distributed beforehand, together with the scenarios), not as an agenda that had to be worked through.

The second step in our approach is the construction of sociotechnical scenarios. Each of the (three) scenarios starts with a specific attempt of actors (often a consortium of actors or an actor at the collective level, like a national government) to overcome the waiting game, and then traces responses, further actions and interactions, and repercussions. ${ }^{2}$ Each of the scenarios highlights a specific path into the future. In reality, different and partial attempts to address the waiting game will occur together, so readers of our scenarios can consider combinations of them when they want to orient themselves to concrete future developments. As is well known, scenarios sensitize and enlighten their users to think

\footnotetext{
${ }^{2}$ We offered three scenarios, not because these exhaust all possible attempts to break through the waiting game, but because they capture the main types of attempts (cf. also [4] on the background of the construction of such scenarios).
} 
more broadly about futures. Our scenarios realize the enlightenment function because they indicate evolving patterns that participants may not have noticed and because they are constructed with the help of insights from technology, innovation, and societal embedding studies.

In the section reporting on the scenarios, we will do two things. We offer the text of the scenarios that was circulated to the participants as an exhibit to allow the reader of this article to see the actual input into the workshops and experience for him/herself our attempt at narrative plausibility. Second, we add annotations so that the reader can see the data, insights, and considerations that have gone into their construction to make the scenarios robust. For reasons of space, only one scenario will be reproduced fully. For the other two, we give excerpts (the full annotated versions are available in [3]).

The scenarios, as reported here, were constructed in 2009. In the final section of the paper, we indicate what could be learned from the discussions in the workshop and consider what has happened since. As it turns out, the overall situation in 2012 is pretty much the same as in 2009 , so our scenarios are still applicable. We base this consideration on two main sources of data. First, the experience in the two interactive strategy articulation workshops about OLAE in late 2009, with different kinds of stakeholders, one held in Eindhoven (partly supported by Plastic Electronics Foundation) and a second one in Heidelberg (partly supported by InnovationLab $\mathrm{GmbH})^{3}$ Second, one of us (AP) has been employed in an EC-funded project, COLAE, where he has interviewed OLAE actors and observed what was discussed in private and public meetings. ${ }^{4}$ This has allowed him to form a fairly robust view on what is happening now and the dynamics that are involved. We conclude our article by briefly reflecting on our methodology.

\section{Dynamics of the development of the domain of OLAE and a diagnosis}

For a long time, the domain of OLAE was (and still is to a large extent) a world in which technology-linked relationships among actors dominate. Business-to-business relationships

\footnotetext{
${ }^{3}$ The work on the scenarios and the organization and conduct of the workshops (including follow-up interviews with all participants) was part of the Ph.D. research of Parandian, funded by the Dutch R\&D consortium NanoNed (http://www.nanoned.nl, last visited 3 March 2013), specifically its program on CTA of Nanotechnology, led by Rip. The support of Plastic Electronics Foundation and InnovationLab was limited to providing a meeting place and helping with the organization. We also found it symbolically important to ally ourselves with actors in the field; these had no say in the construction of the scenarios and the agenda of the workshops and no prior knowledge of them.

${ }^{4}$ COLAE stands for commercialization clusters of OLAE. See http:/ cordis.europa.eu/fp $7 / \mathrm{ict} / \mathrm{photonics/docs/factsheets/colae-factsheet} \mathrm{en.pdf}$ (last visited 3 March 2013).
}

are explored, and "new combinations" are formed across traditional value chains. The increased use of the acronym OLAE to indicate the domain, and its promise, is linked to the broadening of the domain in the early years of the twenty-first century.

The domain started with the discovery of organic semiconducting materials by Shirakawa, MacDiarmid, and Heeger [6], which led to visions about the use of conjugated organic molecules and organic/inorganic composites to function as semiconductors, to emit light, and to exploit the mechanical properties (flexibility) of these materials. This would then create a shift from the present silicon plus lithography-based manufacturing in the electronics industry to potentially cleaner, more flexible, and cost-effective manufacturing processes like printing [7]. The initial focus for organic electronics was the electroluminescent functionality of OLED materials (based on discoveries in the Kodak and Cavendish laboratories). As Sauer et al. showed [8], a lock-in emerged where displays were the main application. However, during the early 2000 s, it became clear that the technology was not ready for market introduction and further research and development (R\&D) activities were necessary. At the same time and, in particular in Europe, the vision of cheaper, cleaner, and more flexible manufacturing opened up the dominant focus on display applications and mobilized wider support for the domain. Eventually, in the Sixth Framework Program of the European Union (EU), running from 2002 to 2006, appreciable resources were allocated to the broader domain.

Generally, the period after 2002 can be characterized as one of expansion in activities across the field of organic electronics. While many large company research laboratories, particularly large material-developing companies like DuPont, Merck, Bayer, and Sumitomo, and also companies like Philips, Siemens, and Xerox were already involved and had committed resources to $R \& D$ on organic electronics, various start-up companies pursued activities in different application fields. ${ }^{5}$ These activities went hand in hand with optimistic projections about the economic and technological potential of the field, which allowed R\&D to continue with a focus on performance improvement of materials and testing in university and company laboratories across Europe, without necessarily inquiring into concrete applications. Promises, up to hype, formed an integral part of the OLAE landscape. Sheats [9] notes how the prevalent notion that organic electronic technology equals low-cost production led to forecasts about economic potential in a variety of

\footnotetext{
${ }^{5}$ Siemens and Leonhard Kurz (stamping equipment developer) formed the printed RFID developer PolyIC in 2003. The technology incubator unit within Philips founded Polymer Vision (developing an e-reader device with a flexible display) in 2004. Nanoident, a start-up focusing on the development of photonic sensor technology based on organic semiconductors, was founded in the same period in Austria.
} 
markets. ${ }^{6}$ The numbers read like a forecasting race: who can top the previous high forecast? However, as developments in different fields did not go as quickly as markets reports assumed, concerns about hype were voiced in some market reports:

A second problem is the seductive vision of "printed electronics". One actually finds marketing communications seriously asserting the expectation that organic RFID tags, for example, will be printed in the same process, at the same time, as the printing of visual labels on packaging. No one familiar with both the science of organic electronic processes and materials and the graphic arts printing environment would put such a vision forward, yet just this idea is probably responsible for driving a significant portion of the $R \& D$ investment in the field. And if so many people are saying it, who wants to be left out? (Sheats [9], p. 1986)

A particular concern was about the underlying assumption that the progress along learning curves would be rapid enough to overtake existing technologies. At least, the assumption remained unchecked in the open-ended promises about potentially disruptive technologies like printed RFID, cheap and disposable point-of-care devices, organic photovoltaics, and OLED for displays and lighting. Gamota et al. [10] added that the promise of low-cost applications was based on the assumption that products would be taken up widely and that low cost would be achieved through economies of scale.

What remained important was the possibility to use the basic components for different products.

As a community we seem to be stepping into a development era of organic electronics. We are making integrated devices and turning them into prototypes. We are also exploring manufacturing concerns associated with our devices and long-term device stability. In essence we are putting our materials, devices and processes through the paces, so that we can see what we can do with organic electronics. The next steps involve figuring out the true and unique advantages of organic

\footnotetext{
$\overline{{ }^{6}}$ Examples are consultancy companies like NanoMarkets and IDTechEx that produced periodic market reports claiming to offer essential guidance to the myriads of market opportunities for the future of OLAE. NanoMarkets, for instance, expected the market opportunities for the transparent conducting oxides, polymers, and nanomaterials used in displays, photovoltaics, and other applications to exceed 6.9 billion US dollars in revenues by 2016. See http://www.prnewswire.com/news-releases/ nanomarkets-issues-latest-transparent-conductor-market-report126134868.html; http://www.nanomarkets.net/market_reports/report/ transparent_conductor_markets_2011. IDTechEx forecasted the market potential for printed electronics to rise to 48.2 billion US dollars by 2017 (http://www.printedelectronicsworld.com/pages/printarticles.asp? articleids $=640$ ).
}

devices, and bringing them to bear in electronic markets. (Kelley et al. [11], p. 4421)

This justified the use of an umbrella term like OLAE. The umbrella term was important to create synergy and connect the different developments at the basic component level, while putting forward a widely shared promise about possibilities of use in a variety of application fields - and thus creating momentum for resource mobilization. The actual level of commitment the various actors were making depended on their assessment of the maturity of technology and its potential profitability. Thus, an important factor in the development of the domain relates to the business models of different actors.

An example is how the printing industry feels uncertainty about value capture and profitability. The inkjet printing industry was profitable because of the sales generated by supplying ink rather than by selling printers. The inkjet business in OLAE is different, and it is not clear how profits can be realized in the new situation. Interestingly, there may be shifts in the value chain, partly enabled by expiring of existing patents on OLED materials. Inkjet companies may then leverage economic advantage by formulating own materials or partnering with firms that have the capability to do so [12]. Such shifts can lead to the emergence of new entities in the value chain, like design houses for products with different specifications.

Other examples of pressures on existing business models are in the materials industry. Upstream actors play a key role as materials are crucial for device performance. There is a lot of trial and error in materials development and use, which is exacerbated by the uncertainties about OLAE applications. Exploring the performance requirements of materials for specific inkjet techniques requires material suppliers to form new alignments with ink manufacturers and printer manufacturers [12]. A subsequent challenge is that the amount of materials used in the printing technologies is much less than in the traditional deposition technologies. In other words, if the promises of OLAE are realized, this will disrupt present business models: Traditional chemical suppliers are used to sell large volumes of materials, but in the new situation, they must adapt their pricing strategies. They must learn to produce for niche applications of organic electronics.

The overall picture is one where actors monitor developments of options in the domain of OLAE, as well as actual and possible strategies of other actors. The uncertainty about options and moves at the side of materials supply creates challenges for more downstream technology developers and product integrators, almost forcing them to take a wait-andsee position. The uncertainty about technological developments particularly increases the risk for actors to commit resources, so that they wait for the necessary parts of the system to be developed-somehow. 
One such challenge is the need to develop encapsulation techniques and materials. Encapsulation is a critical problem in realizing organic electronics products because organic materials are highly sensitive and fragile and deteriorate when exposed to oxygen and moisture in the air [13]. While shortcomings in encapsulation are recognized as constituting a reverse salient for the further expansion of OLAE, work on them is limited because return on investment is uncertain - it depends on whether the expansion of OLAE will materialize. ${ }^{7}$

As the OLAE landscape was becoming more crowded, anticipatory coordination in the field became important and was pursued. An important actor is the Organic Electronics Association (OEA), established in 2005 as an information and communication platform by companies and institutes active in this domain. One of the main activities pursued by OEA besides promoting the potential of the field in policy and commercial domains has been in facilitating the development of application roadmaps as a way to articulate expectations. But this was not enough. In a presentation titled "The status and future of organic and flexible electronics", in December 2007, Michael Heckmeier (Director at Merck Chemicals Ltd. UK) explained that the reason why the market of organic electronics is not "exploding" has to do with the combination of considerable uncertainty on the technology side and at the same time lack of interested end users. ${ }^{8}$

Since about 2007, the issues related to demand articulation for different applications of OLAE were higher on the agenda, but it was not easy to do something about them. Basic market knowledge as to who the actual customers might be and what they actually want is limited and is actually hard to come by since the customers are still unknown. For a long time, the recognition of the issues led to concerns rather than action. An example is this quote from an interview with Martin Schmitt-Lewen (manager of functional printing at Heidelberg Company):

I can't see Heidelberg commercially printing electronics or developing the equipment for a long while yet and there is no point in developing a printing kit or system when there are no existing customers ready to buy them, considering very few companies in the printed electronics market are scaling up production, particularly in RFID and active packaging space, there is no requirement for large print press systems.

\footnotetext{
${ }^{7}$ A reverse salient is a subsystem that blocks further expansion of the entire system, so that that improving other subsystems will not make a difference as long as the reverse salient is not overcome [18]. The concept and the phenomenon can be relevant for other emerging technologies as well.

${ }^{8}$ http://isfed.itri.org.tw/2007/files/presentation/Michael_Heckmeier.pdf (last visited November 2011).
}

He further argued: "We want to avoid speculatively developing equipment or printed electronics products until the technology and the market are more mature." 9

It is clear, also to quite a number of actors, that some concerted action is necessary, within value chains and across them, to overcome the waiting game and realize at least something of the promise of OLAE. The other route is visible in the conclusion of a competence matrix study by the University of Reading on plastic electronics in the UK: "There is no incentive for companies to develop compatible standards or push for common technology platforms without a powerful end-user to insist on this" [14]. This implies another way to overcome the waiting game: action by a powerful end user, for example, a national government introducing a procurement program for a set of products requiring OLAE technology. (We have actually taken this option as the starting point for our second scenario.)

The diagnosis is clear: uncertainty about technological developments in the field of OLAE increases the risks for actors to commit resources, and this translates into a situation where actors will have to wait for the other parts of the system to be developed. Lack of articulated demand, and the differences across sectors, exacerbates the situation, in the sense that concrete directions of product development are not clear and actors have to refer to promises in making choices. Key actors like material suppliers and printing equipment manufacturers anticipate changes to their current business models, but are reluctant to move. Actors face tensions, up to dilemmas, and anticipatory coordination problems.

The next step in our diagnosis is to use insights from technology and innovation studies to identify key dilemmas - this is a way to highlight what the stakes are, even if they are not always as clearly visible as we formulate them here. Such dilemmas, often applicable to emerging technologies more generally, are building blocks in constructing scenarios because they show tensions as well as potential forks in the story line, depending on which horn of the dilemma is followed. They are also helpful in highlighting the nature of the situation to the participants in the strategy articulation workshops. ${ }^{10}$

A first and important question (although rarely checked concretely) is whether the new technology will progress at a sufficiently rapid pace along its learning curve to overtake existing technologies, also because existing technologies will improve and present value chains and markets may not welcome the new technology. The response could be: hope for the best because the promise will mobilize resources. But one might also be more careful about relying on promises

\footnotetext{
${ }_{9}^{9}$ Plastic Electronics Magazine (2009): What is Heidelberg's real plan for printed electronics? Volume 1 , issue 6.

${ }^{10}$ A brief version of the diagnosis outlined in this section, together with a list of dilemmas, was part of the preparatory material for the workshops.
} 
and focus on realizing immediate performance improvements and production capacity ramp-up - while reducing one's ambitions.

A second question is about market entry strategies. The disruptive nature of applications of OLAE creates a choice whether to go slowly or try to build on the promise. In other words, early market introduction in niche applications only, while embedding in society is tested out, or early market introduction without checking societal robustness. In the field of organic solar cells, the second strategy is very visible, while for point-of-care sensors in health care, the first strategy is (or should be) followed to meet the requirements of the health care domain.

A third question is about relying on government support, which implies that public goals have to be taken into account (like wealth creation and sustainability). One strategy to reduce uncertainty is to go for strong and dedicated government support and accept that it comes with a need to refer to the public interest - which then opens the door for comment and criticism in terms of public interest. (This possibility will actually be explored in scenario 1.) The other strategy is to accept all the risks of realizing technical and market requirements and profit from government support (e.g., to stimulate market adoption of societally important products through subsidies) when it happens to coincide with own activities.

In these three questions, we identified with technology and business actors and discussed their strategic choices. A fourth question starts with government actors having to make strategic choices; innovation policy studies have addressed such issues. In the case of emerging technologies like OLAE, governments are justified to stimulate the development of such technologies because firms in the marketplace will invest suboptimally: the so-called market deficit. But governments do not necessarily have the competence to make the right technology choices: the so-called government deficit, actually a competence deficit at their side. Thus, governments have to balance between the amount of risk they are prepared to take and the criticism that they might be subjected to if this risktaking leads to failures and, in any case, to opportunity costs. The dilemma is to go for dedicated support, facing the risk that there will be little value for the public money expended, or to play a modest role, just creating favorable conditions like fiscal regimes and adequate intellectual property regulation, accepting there will be suboptimal developments.

\section{Three scenarios}

Each of the three scenarios shown in this section builds on what might happen when a specific way to address the waiting game and tensions and dilemmas more generally materializes. Only for the first scenario is the text, with annotations, given in full so that the reader of this article can appreciate how participants could recognize themselves and others in the description of the present situation and immediate future, and then be taken out of their commonsense ideas by being confronted with unexpected but plausible futures. This created a context for participants of our workshops to think anticipatorily and interact in terms of each other's realities and possible strategic actions.

The genre of writing is quasi-factual: the future is told as if this is what happens. This may be disconcerting sometimes for a reader in 2012, as when the opening line of the first scenario says: "In Dresden, late 2009, one OLAE firm got into trouble and another one moved to South Korea." We have not updated the text because it is an exhibit. At the time, for the participants in the workshops, it was formally part of the future, but a real possibility (cf. the annotation). Thus, there is some blurring between the formally fictional future and the factual (in the sense of "has happened") elements of the present situation that are used in the scenarios to create a sense of continuity with the future. In the introduction, we argued for this in terms of our approach of endogenous futures. Here, we add a communicative function: enrolling participants of the workshops into the scenarios as a world they know that gradually turns into a future that they have to take into account in the here and now.

To introduce the scenarios, we offer brief outlines showing the key interventions (fictional but plausible) that set further developments in motion. The first scenario starts with a concerted effort, enabled and financially supported by the EC, to develop applications, particularly for lighting, to mobilize users and to include further stakeholders like environmental groups. There was some debate about the relevance of pursuing this direction, and this returned when the actual performance turned out to be disappointing. Some big actors withdrew from the joint initiative, and this was a signal to shift directions (to applications in photovoltaics). In retrospect, important learning had occurred, even if the joint initiative had not been able to realize its original goal.

The second scenario starts with the decision of the UK government (later joined by other governments) to use procurement to materialize the promises of OLAE. The actual procurement was linked to the challenges of security and focused on e-passports with OLAE-enabled RFID and display. This initiative was an argument for Germany to also stimulate OLAE, but then for organic photovoltaics, and not through procurement but by supporting pre-competitive development focusing on generic problems like encapsulation techniques. Spillovers of these two developments occurred, but the procurement program collapsed because security, now of the passport holders, could not be guaranteed. One effect was that use of RFID shifted to "safe" applications like retail and entertainment. Organic photovoltaics could not deliver on all its promises, but there were important applications because of new collaborations in sectors like the building sector. 
The third scenario starts with actors in the product value chains willing to get together. A strategy discussion meeting organized by big materials companies triggered a variety of alliances between companies across product value chains and joint technology development. Progress was made at the manufacturing side, although market introduction at first suffered from product quality problems. Price reductions reduced adoption barriers and created new possibilities, for example, for cheap sensors for medical and environmental applications - provided that the quality requirements could be met.

\section{Scenario 1: concerted efforts and learning}

In Dresden, late 2009, one OLAE firm got into trouble and another one moved to South Korea. The Frankfurter Allgemeine Zeitung wrote this up and called for action. ${ }^{11}$ The ensuing debate was taken up in other European countries and broadened to discussion about the competitive position of Europe in high-tech areas. The European Commissioner for Trade, who had wanted anyway to take an initiative towards wealth creation as a response to the economic crisis, but also shaped by the wish to revive manufacturing, as well as to build on earlier investments of the EC, saw the debate as an opportunity to do something, starting with the establishment of a High-Level Expert Group (consisting of academic, policy, and industrial actors). ${ }^{12}$

The report argued that Europe has a frontrunner position in the field of OLAE compared to other regions (USA and Asia) that was created through the $R \& D$ investments in this field. ${ }^{13}$ It was highlighted that Asian companies were leveraging existing standard manufacturing (linear evaporating line); this was indicated by the announcement of a Japanese venture (Lumiotec) to start a pilot manufacturing site to develop OLED lighting which are flat and thin but rigid. ${ }^{14}$ The conclusion was that moving towards a stronger

\footnotetext{
${ }^{11}$ A few European giants have been divesting or shutting some or all their activities in OLAE. In contrast, activities of East Asian giants have been growing. Report of IDtechEx "Is Europe Losing the Race?", 20 August 2007 (http://www.idtechex.com/products/en/articles/00000669.asp). Also, acquisitions of key European IP holders like CDT by Asian giants like Sumitomo.

${ }^{12}$ Governance is located at the macro level of coordination; cf. the launch of the European Economic Recovery Plan at the end of 2008 called for an Initiative, based on the Manufuture European Technology Platform and related Sub-Platforms, including European Technology Platforms in the field of manufacturing.

${ }^{13}$ Reported by the FP 6th \& 7th R\&D OLAE Project Portfolio (European Commission [19], pp. 14-15 and 36).

${ }^{14}$ Indicated by the announcement of Prof. Junji Kido from Yamagata University in 1st Plastic Electronics Asia (Millennium Seoul Hilton Hotel, June 24-26, Seoul Korea) announcing an OLED lighting panel factory, this was by far the largest initiative in East Asia in the field of OLED lighting.
}

involvement in large area production potentially with organic electronics is an opportunity for Europe. ${ }^{15}$ But also a strong diagnosis: lack of user involvement and working on unproven manufacturing technologies would make investments from industry difficult in the OLAE field. ${ }^{16}$ Without continuity in dedicated funding to stimulate developments in manufacturing, investments made under the sixth and seventh framework projects might not lead to wealth creation in Europe. If not remedied, that would cause the European position in the mid-term to be weakened and eventually to lose its frontrunner position to the USA and Asia. ${ }^{17}$ Organic photovoltaics and flexible OLED lighting were identified as promising options for the EC initiative. ${ }^{18}$

The Expert Group created focused working groups to assess emerging technologies with added value for the European economies. OLAE was one such field, seen as enabling new approaches towards ambient intelligence with novel approaches to make efficient lighting, displays, and low-cost electronics. ${ }^{19}$ Branch associations had already taken initiatives to make the promise of this area visible by specifying a broad range of possible applications and

\footnotetext{
$\overline{15}$ The promise of large-area manufacturing is the most important promise resonated and put forward by the enactors in the OLAE field. The following quote from the Strategic Research Agenda is illustrative: "This new manufacturing landscape creates opportunities for new kinds of industrial players, in addition to the existing electronics industry value chain, to join the OLAE community building the future technology backbone of European excellence and business creation" (Strategic Research Agenda [20], p. 7). I have also verified this with data gathered from desk research, interviews, and seminar visits.

${ }^{16}$ This diagnosis is resonated in almost all interviews I had with the enactors who were active in developments of OLAE in the Netherlands. The diagnosis is also visible in the conclusions of round table discussion at Organic Electronics Stakeholder Meeting EU Commission-30 May 2007 (ftp://ftp.cordis.europa.eu/pub/fp7/ict/docs/events3-20070530minutes-on-oe-meeting_en.pdf); see page 2.

17 The recent SRA "Towards Green Electronics" presented to the EU commission explicitly requests an increase in the funding budget in proportion to the huge expected markets (Strategic Research Agenda [19], p. 5). This message also resonates in different occasions where enactors interact with the EU commission, cf. presentation of Wolfgang Clemens (chairman of organic electronics association) at OLAE stakeholder meeting-EU commission, on 1 October 2007 in Brussels.

${ }^{18} \mathrm{My}$ case research in expectations clearly shows that flexible OLED lighting and organic photovoltaics are viewed as most promising options of OLAE for the EU, most importantly in the UK, the Netherlands, and Germany. My case research shows that OPVs have made advances based on the learning curve in OLED lighting. Indicative is the EU funding under the FP7 framework that has allocated 42 million euros on OLED lighting projects. The importance of solid-state lighting is such that $63 \%$ of the first call funding for OLED developments has been allocated to OLED lighting projects.

${ }^{19}$ From my discussion and interaction with Arun Junai from TNO Netherlands and Ed van de Kieboom from Plastic Electronics Foundation (August 2009) on the draft of multi-annual roadmap resulting from the work of the ad hoc Industrial Advisory Group of the Factories of the Future Public-Private Partnership. The discussion revolved around the representation of OLAE activities in Europe within the roadmap.
} 
components that made use of various materials like organic, inorganic, or hybrid materials and fabricated via large-area mass manufacturing processes. ${ }^{20}$ Such open-ended promises about next generation information technologies, energy, health care, and entertainment solutions, and social benefits could now be linked to the general aims of the EU initiatives. The team of experts in this working group produced a first white paper, presenting a strategic assessment of opportunities and threats for Europe. ${ }^{21}$

The report did not create a big stir, but reinforced the positive atmosphere around OLAE, in which possibilities were explored, European regions put the technology on their agenda, and an occasional imaginative venture capitalist supported a small and medium enterprises (SME) branching out into this area. ${ }^{22}$ The focus on lighting as an important area of application was supported by the new EU regulation to phase out traditional light bulbs. ${ }^{23}$

The advice of the High-Level Expert Group, including a priority for OLAE, for lighting was included when the EC announced a Joint Technology Initiative (JTI) on "the factories of the future" later in 2010. Manufacturing was the key challenge, and the first step was a consultation process. European Technology Platforms (e.g., Photonics21, European Nanoelectronics Initiative, Clean Environment Technologies, etc.) were included in identifying promising areas of high value which deserved strengthening beyond the framework programs. ${ }^{24}$ Incumbent industrial players in lighting said that flexible lighting foils were a promising route. They argued that

\footnotetext{
$\overline{{ }^{20}}$ The Organic Electronics Association (established in December 2004) is a working group of the Verband Deutscher Maschinen- und Anlagenbau e.V. (the German Engineering Federation) has made large efforts in making the promise of OLAE visible, specifically by making comprehensive application roadmaps where the promise of organic electronics is made visible in a variety of applications in multiple sectors [21].

${ }^{21}$ At the time of scenario development, a new strategic research agenda titled "Towards green electronics in Europe" was developed (September 2009) where the OLAE umbrella promise was related to grand challenges and societal themes (like global warming, embedded intelligence, etc.) linking up with EU initiatives that aim to solve these issues. ${ }^{22}$ Showing gradual movement in "innovation journeys" from gestation to start-up phase. While VC's are not really interested in investing in unproven technologies, the interest in clean and renewable energy is attracting more interest and financial resources. There is also visibility of occasional VC investments, cf. Konarka (OPVs) and Plastic Logic (e-paper). From my desk research and interview with a venture capitalist (Jelto Kromwijk Smits-Partner at Prime Ventures) active in OLAE. ${ }^{23}$ The enactors in the lighting field shows that they expect these macro governance measures to stimulate a market for energy-efficient lighting. This was confirmed in my interaction with lighting experts.

${ }^{24}$ At the time of scenario writing, I was aware of the initial discussions on the preparation of a draft Draft Strategic multi-annual roadmap the factories of the future. This was based on a real initial stakeholder consultation process (including various EU technology platforms mentioned in the text). My interactions with the director of Plastic Electronics Foundation and coordinator of the EU-funded OPERA project, Ed van de Kieboom, provided this information.
}

organic photovoltaics lagged behind in development, particularly with respect to encapsulation. Leveraging advantages of (rollto-roll) manufacturing would eventually enable cheap OLED lighting applications to compete in the general lighting application market and thus lead to wealth creation. ${ }^{25}$ Issues were identified by various parties. The spokesperson of a coordinated EU Framework project emphasized the promise: "We demonstrated high quality lamination foil for flexible lighting and the opportunity that these technology platforms can be used in other low-cost electronic devices as well. Leveraging on these findings is of key strategic importance for future product development trajectories in Europe." 26 The CTO of a large material developer focusing on OLED lighting materials said: "The OLED market will have two parts, displays and lighting. Asian companies dominate the display industry and there is little hope for Europe to get this back. For OLED lighting it is different, because lighting production still exists in Europe with large players like Philips and Osram. This is an emerging market with lots of opportunities especially because of the tendency of large lighting companies to direct their investments and resources into OLEDs for lighting."27 There were also sounds of caution as in the speech of the chair of the Energy and Sustainability Committee of the European Association for Lighting Designers: "Inflated claims about performances of LEDs in the past created skepticism in the designers' community making them cautious in recommending LED luminaries. OLED manufacturers should avoid hype about product performances and bring well tested products to the market., 28

The net effect was that the promises for lighting applications were accepted by the EC and support was forthcoming for an alliance with big incumbents which would focus on roll-to-roll manufacturing of lighting foils. ${ }^{29}$ Earlier experience with

\footnotetext{
${ }^{25}$ Umbrella promise of organic large area electronics: roll-to-roll manufacturing would reduce costs of production of OLED lighting, offering opportunities to compete with other products and technologies in the general lighting market.

${ }^{26}$ Stylized quote: Leveraging on previous work on high quality lamination foils which can also be used for other low cost electronics (from desk research in news letters of coordinated EU framework funded project Fast2Light and OLLA).

${ }^{27}$ Stylized quote from an interview with a CTO of a material developer Novaled (Jan Blochwitz-Nimoth) for OLED lighting (in an industry magazine): Dominance of Asian companies in displays leaves little hope for EU to enter this market but existence of European giants (like Philips and Osram) in the lighting market is hopeful because production is still in EU.

${ }^{28}$ Stylized quote: from the announcement of the chair of International Association of Lighting Designers Sustainability Committee (Glenn Heinmiller) in an industry magazine issuing a warning drawn from lessons of LED's about inflated claims about performances.

${ }^{29}$ Expectations about the potential of OLAE in flexible lighting become forceful through the backing of strong governmental support. Other modes of governance, e.g., phasing out of incandescent light bulbs, provide additional support to the promise of the potential to enter general lighting markets (so open up room for product/market expectations).
} 
promises which were not realized prompted the EC add a monitoring scheme, with a requirement for at least some short-term results. Now, there was further justification, emphasized in the presentation of the draft proposal in Brussels, that the difficult economic conditions in Europe required investments in R\&D to make significant societal and economic contributions within a few years. ${ }^{30}$ Not everyone was happy with this requirement. As a spokesperson for an R\&D company said: "these requirements bureaucratize the process, which make the whole funding procedure inefficient." Eventually, participants were willing to accept this requirement as a temporary instrument. The funding support from EC and credibility of efforts that came with it allowed uncertainties of developing new unproven manufacturing capabilities for lighting to be reduced and standardization of manufacturing lines be improved. These advantages were widely recognized. ${ }^{31}$

The representative of Professional Lightings Design Association (PLDA) was quoted in a news article explaining that their engagement would open up the opportunity to make an actual difference in the new developments within the lighting industry, instead of coming in at a late stage: "Our engagement opens up the opportunity to identify and engage users in early stage. We will also collaborate in measurement activities to provide reassurance to the designer's community about different performance promises. This will prevent past mistakes made with LED luminaries."

When the JTI was eventually launched, early in 2011, an interesting further move became visible. A spokesperson of a lighting company proposed (but after careful preparation and consultation) to include design associations and nongovernmental organizations (NGOs) in the initiative, as a strategy to show that it was more than following promises: "Our activities shouldn't only focus on solving technical issues, we also need to consider requirements of end-users." He had been able to convince the PLDA and Friends of the Earth, an NGO focused on technology and environmental issues, to engage in the JTI. Good feelings were voiced, and concerted work started immediately. ${ }^{32}$

\footnotetext{
${ }^{30}$ Such requirement has been taken up in the draft proposal by the advisory Group of the Factories of the Future Public-Private Partnership which indicates new strategies taken up in governance modes towards better societal embedding (published on13 July 2009). The document explicitly mentioned that, in current difficult economic times, R\&D in EU should start to pay back within 4 years and make significant contribution to sustainability of society in EU.

${ }^{31}$ Here, I use insights gained from my interviews with the main enactors in the field who have repeatedly emphasized the need for strong government support for the development of new unproven manufacturing technology and its standardization. All of the enactors interviewed emphasized a deficit in funding for manufacturing, production, and demonstration. Hence, while enactors may complain about extra bureaucratic burden, they accept monitoring measures because the resources provided reduces their uncertainties.

32 This is taken up to show how substance can be given to the monitoring task. The strategy of engagement with broader actors becomes serious when they are included and a space for interaction is created.
}

The OLAE landscape in Europe now became dominated by the challenge of OLED-based lighting applications. ${ }^{33}$ There are three strands in the story: the JTI and its fate, responses to the European initiative, and other OLAE activities going on as well.

The strong support in Europe for a collaborative approach focusing on flexible OLED lighting applications implied a competitive challenge to which the Japanese company Lumiotec had to respond. Kido, the scientific director, recognized the advantages that roll-to-roll manufacturing might have in lighting applications, but announced a pragmatic strategy at the annual international technology expo in Japan, "We have been able to solve issues with production and performance in the past two years in our pilot setting and our partners are convinced we can have the first mover advantage, so we are planning to scale up production in 2012." They would increase their efforts to enter the lighting market. ${ }^{34}$

Other application areas of OLAE were pursued mainly by SME's and start-ups from research institutes or multinational electronic companies. Especially in Germany, support from Bundesministerium für Bildung und Forschung (BMBF) made further work possible on printed RFIDs and organic printed photovoltaics. ${ }^{35}$ Printed RFIDs and organic printed photovoltaics were being tested in pilot settings, and ereaders were further developed and first flexible e-readers of Plastic Logic were explored in niches. ${ }^{36}$

By 2012, while developments in flexible lighting continued at a pace, the hopes of Plastic Logic were confronted with

\footnotetext{
${ }^{33}$ Emerging irreversibility: In the EU, the combination of broad promise on flexible lighting and the EU-supported JTI program on manufacturing enables the creation of a monstrous alliance. This strategic consideration leads to the creation of a specific path/trajectory within the broad possibilities in the OLAE landscape. Other OLAE activities are ongoing, but it is emphasized here that a strong focus is created on OLED lighting due to the circumstances created in this scenario.

${ }^{34}$ At the time of scenario writing, Lumiotec was considering to scale up its pilot production by 2012 , which was the time expected by lighting market forecasts for OLED lighting to take off. This also shows movement in the innovation chain from optimizing and improving innovation process to realizing of achievements and market entry. From my desk research, especially an interview given by Junji Kido (the first scientist to publish a paper on white OLED in 1993), and background article about Lumiotec activities (industry magazine, Plastic Electronics, volume 1 , issue 4, p. 33).

${ }^{35}$ The Federal Ministry of Education and Research (BMBF) plays a key role in Europe to enable printed electronics. Since 2004, with the setup of the microsystems framework, the BMBF has enabled a range of projects by mobilizing financial support. Projects on RFID (e.g., PRISMA, PESEL, PRIFAX, TexTralog) and together with BASF, BOSCH, MERCK, and Schott, a 300 million euros project to develop OPVs further.

${ }^{36}$ Movement in "innovation journeys" towards exploration and experimentation and niche testing phase. Plastic Logic is the first company to set up a production line in Dresden, Germany to produce organic-based e-reader displays was planning to start production by 2010 . This planning was delayed for unknown reasons at the time of scenario writing.
} 
disappointing uptake of their e-reader. Traditional publishers were not adapting, and debates on intellectual property rights spilled over in this domain. The need to have severe restriction on piracy had caused different platforms to emerge that were not compatible. The e-reader industry was struggling. ${ }^{37}$

A lateral effect was that E-Ink, the main technology supplier, devised strategies to stimulate expansion of use of its technology to other application areas. A breakthrough in the developments of thin film batteries had made it possible to integrate the displays in magazine covers. In a technology expo organized in Dresden, Germany, E-Ink's CEO announced contracts with various magazine publishers. Its CEO said "Our unique technology will change the future of publishing and opens a new chapter to advertising." Esquire magazine had been the first to try the technology a few years earlier and was explicitly mentioned to be the first contractor. ${ }^{38}$

The intended announcement effect, to mobilize for wide deployment of E-Ink displays in magazines, had an unintended effect when it incited negative reactions from environmental groups which argued that the new applications E-Ink aimed for meant an increase of environmental burden. Greenpeace started an electronic campaign under the slogan "Esquire magazine, the Darth Vader of electronic reading," saying that the publishing industry should put their thinking cap on. There were mixed reactions in the sustainability community. As a result, magazines across Europe felt they had to publicly announce they would refrain from using the electronic magazine cover option. ${ }^{39}$

Two years after the start of the JTI, the first reporting round in 2013 showed efforts at technology development,

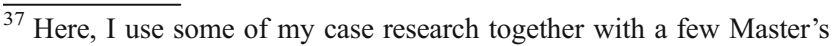
students into expectations in the e-reader sector (exploring issues like open platforms for content and different standardizations). This helped to describe lateral developments and possible anticipated effects in the e-reader sector. Furthermore, the struggle in the e-reader industry, which is mainly related to the different strategies of traditional publishers and the dependence of e-reader developers, was confirmed in my interview with Alex Henzen, CTO of iRex (an Eindhoven-based startup working on the developments of full color e-readers).

${ }^{38}$ This piece of the scenario tale is based on the controversial move of E-Ink that has provided the first electronic magazine covers for the October issue of Esquire magazine (100,000 issues were released), but there were difficulties with the batteries. Batteries form a reverse salient in the system because of their large form factor. My desk research (including the report of Zella King from University of Reading: Plastic Electronics: Putting the UK at the forefront of a new technological revolution, pp. 14-15) in expectations indicates that a breakthrough expected in energy sources in a thin, flexible format will cause a further move of displays into the advertising market.

${ }^{39}$ E-Ink's collaboration with Esquire has been met with mixed reviews in the sustainability community. The promise of E-Ink on one hand is that it will contribute reducing paper production through e-readers. However, the collaboration with Esquire raised questions in the media whether this promise would only be for a short period and anticipations that the use of the technology in other sectors would eventually cause more harms (because of the large $\mathrm{CO}_{2}$ footprint it leaves behind). An unintended effect! The text shows comparative selector thinking and how the developments lead to broader societal concerns.
}

but also reflected a concern, emphasized by PLDA representatives. According to industrial standard tests, the performance of lighting products produced in the pilot line appeared to be lower than required for general lighting applications. It appeared that much more R\&D by material developers was needed on solution processable polymer OLED materials to optimize the performances required for general lighting applications. ${ }^{40}$ In addition, the costs now incurred in material development and production would lead to prices unfavorable to the competitive position of OLEDs against other lighting applications in the market. The strategic review recognized that products for lighting design applications and signage applications for advertising would still be feasible before the project ended. ${ }^{41}$

Thus, in contrast to the original high hopes, the products developed might well remain limited to niche applications where the flexibility of the application was seen as a key advantage and lower performances were acceptable. There were already examples. Through PLDA, contacts were made with the design team of the German automobile manufacturer Daimler and airplane manufacturer Airbus. Daimler had announced to use flexible lighting in the dashboards of its new S-class Mercedes. Concurrently also, Airbus announced that the flexibility of lights was seen as a key advantage to be used in airplane lighting designs and ordered the lights for the

\footnotetext{
$\overline{40}$ The large efforts focused on manufacturing had blinded the enactors for the issues and difficulties in optimizing performances of solution processable polymers. Blinded by the promise of roll-to-roll manufacturing (this is the process of creating electronic devices on a roll of flexible plastic or metal foil; this processing technique is also used for applying coatings, printing, or performing other processes starting with a roll of a flexible material), which was cleaner, more sustainable, and most importantly, that it would enable much cheaper production of OLED lighting so to be competitive in the general lighting market. For roll-to-roll processing, see http://en.wikipedia.org/wiki/Rollto-roll processing. In OLAE, there is a large interdependence between process optimization, device architecture, and material design which can lead to long development times. Some experts in the field expect the optimization of light performances with soluble materials that could be printed to take more than 10 years at the time of writing this scenario story. Besides efficiency, stability and lifetime are important factors for the development of OLED lighting which are dependent on advances in encapsulation techniques. Encapsulation in OLED lighting forms a reverse salient in the technology system of OLED lighting. Thus, the overall performance of the lighting application developed by the roll-toroll manufacturing is dependent on advances in other fields as well. The scenario tale also shows that the inclusion of PLDA has led to early identification of the issues with performances. My desk research and interview with Prof. Paul Blom of Holst Centre and Peter Visser of Philips Lighting show that there is a need for standardization of measurement. The involvement of a professional user association is a key step towards this goal.

${ }^{41}$ Costs are one of the largest issues for OLED lighting manufacture. That is why roll-to-roll manufacturing offers such a big promise to the field. From my interview with Peter Visser (Philips lighting and Manager of the EU-funded OLLA project). This was also confirmed by my desk research in expectations of other key industrial actors about cost competition in the general lighting sector.
} 
A380. Other design applications for indoor lighting were also being pursued by specialty lighting design companies. ${ }^{42}$

Independently, Friends of the Earth reacted skeptically to the course of developments with the sudden shift towards design lighting applications. Ruth Walther from Friends of the Earth Germany queried how the overall energy efficiency promise of the JTI could be realized if it only remained a design lighting application to be used besides other applications or as advertising signage application which would only encourage more energy usage. She was quoted criticizing the earlier choices made by EC to invest in lighting applications: "the promise of wealth creation that was embraced for lighting applications had blinded people to see other developments that were occurring and which might score better on sustainability." The reference was, in particular, to ongoing activities in Germany (supported by BMBF) focusing on organic photovoltaics. In response, it was pointed out by scientists in the JTI that uptake of organic photovoltaics had been problematic as well because of technical difficulties with encapsulation and strong competition with other available technologies. ${ }^{43}$

The signals given by Friends of the Earth were used by green-oriented parties in European Parliament in the debate in Parliament about the sustainability policy of European governments and companies (together with electronic displays in magazines as an example of carelessness in dealing with environmental aspects). The critical question was raised whether EC investments in the JTI on lighting will ever realize the promise of reduction of energy consumption. As a Green Party MP summarized it: "European citizens expect governments and companies to deploy sustainable strategies in product development." ${ }^{44}$

\footnotetext{
$\overline{42}$ Niches have to be explored where higher prices can be charged and lower performances are acceptable. The inclusion of the professional user group opens opportunity to explore niches different designoriented markets. We explicitly introduced this point in the scenario because of the diagnosis of the lack of articulated demand during interviews and case research. Interaction of professional designers as comparative selectors early in the project creates transparency about performances and measurements. Professional users have access to potential customers, and this way, it is easier to match supply and demand even though it concerns small niches here.

${ }^{43}$ Concerns voiced by critical comparative selectors. The concerns were voiced in a group discussion/interview I had with a number of professional lighting designers from The Atelier LEK in Rotterdam, the Netherlands who critically examine the sustainability promise of lighting applications in context of their use. I use this insight here in the scenario because it enables to create a shift in the story line and to show the message that promises in this case of wealth creation can enable certain path's trajectories while containing others. So, emerging irreversibility occurs.

${ }^{44}$ Micro level disappointments have exposure and are taken up in macro level debates concerning the responsible innovation issues. There is positioning at the macro level. This is partly an effect of ambivalences inherent to novelties such as OLAE: on one hand, its promise to enable green electronics and, on the other hand, risks that become visible as applications are used in different contexts.
}

By 2014, actors from the lighting industry and more broadly had realized that the rhetorics of breakthrough were not sufficient to create a learning curve that would overtake competing of existing technologies in the lighting market (fluorescent, halogen, and LED), especially when these were improving as well. The high hopes for reducing costs through new manufacturing processes had entailed some neglect of other aspects like efficiency and longevity. ${ }^{45}$ Further competitive pressure was visible in the construction sector because of pressure from the European Energy Performance of Buildings directive that aimed at achieving strong energy use reductions by 2019. Lumiotec was leveraging on the use of highperformance materials that were processed in standard evaporation lines and the demand for flat OLED panels was rising. ${ }^{46}$

In this situation, a major move occurred when a big incumbent, Philips, recognizing the dynamics of supply and demand, announced that it would start producing OLED lighting panels in license from Lumiotec. ${ }^{47}$ This undermined the credibility of the ongoing JTI, and the OLAE landscape in Europe started to shift.

In the 2015 participants' meeting in Brussels, the JTI coordinator evaluated the situation: "We have been able to make large steps forward in this project, but to compete in the market for general lighting challenges have to be solved on the materials side. This will take longer than we expected. It is still possible to use the manufacturing technology platform developed in the JTI for production of organic photovoltaics. But the requirements for encapsulation are tough and have to be addressed". ${ }^{48}$

The EC immediately embraced the proposal to shift the focus to organic photovoltaics to show their intent to provide solutions to some of society's biggest problems, such as

\footnotetext{
${ }^{45}$ This piece of the scenario mirrors the diagnosis in the case study on OLAE: The broad promise of OLAE has become particularly interesting because the underlying technologies enable disruptive functionalities to various products across different markets. However, the reference to "disruptive" relies on the assumption that the technology will rapidly progress along a learning curve and thus overtake existing technologies. But it is not certain that this will happen. Existing technologies will also improve, and value chains and markets may not be conducive to the new technology.

${ }^{46}$ Macro level pressure opens up new market opportunities for efficient lighting (based on the European Parliament's directive on Energy Performance of Buildings Directive published on 1 April 2009) which required a very high level of energy efficiency of the building.

${ }^{47}$ Bruno Smets (Philips Lighting) explains in an interview that, when market dynamics of supply and demand are in force in the OLED field, Philips won't rule out buying from oversea developers, referring to the buying of energy saving lamps from China. Interview (in the industry magazine, Plastic Electronics, volume 1, issue 4, p. 37).

${ }_{48}$ The concerted effort has enabled learning to occur, even though the high hopes were not achieved. The combination of EU funding and broad promises at the start of this scenario created an opportunity to breakthrough waiting games because of the strong initiative, but then the performances requirements may be difficult to achieve. Would smaller and slower steps be more productive? Would it allow more room for learning?
} 
climate change. The JTI followed, with some grumbling of participants, and a new promise was put upfront: Cleaner and renewable energy thanks to photovoltaics. The weaknesses were recognized as well, and new collaborations were forged with materials suppliers that specialized in encapsulation applications of photovoltaics. A preliminary analysis of the public consultation on the future of JTI showed widespread support among stakeholders for the new move.

When the original coordinator of JTI was interviewed for the Christmas 2015 issue of The Economist, and the interviewer asked whether "with the benefit of hindsight it might have been better to focus on organic photovoltaics from the beginning rather than lighting," he got a nuanced answer. "The drive for wealth creation at the time may have biased us, but important learning occurred, in particular that a major hurdle existed in the problems with encapsulation. You need a concerted effort to learn such things that were not clearly seen in the beginning. Even if the original goal wasn't achieved, the investment may have been worth it."

\section{Scenario 2: marriage of procurement and promises}

For reasons of space, only excerpts of the full text are given. The deleted parts are indicated by square brackets, and sometimes a summary is provided to keep the storyline visible.

At the level of national governments all over Europe, there was a tendency to abstain from stimulating specific technologies - sadder and wiser because of earlier such projects that were not so successful - and to rely more on procurement to stimulate innovation. ${ }^{49}$ Traditionally, Departments of Defense had worked with procurement contracts. This was now extended, again with reference to the public interest, to goals like internal and external security and clean energy production. ${ }^{50}$ The implication was a reluctance to buy into

\footnotetext{
$\overline{49}$ It is interesting if not unusual that the innovation actors in this field are involved in various publicly funded projects where there is symbolic support to perform R\&D based on open-ended promises. But the promises are too uncertain for actors to initiate concrete promiserequirement cycles (because it involved high risk). We reduce the complexity here on purpose by showing that the broad promises are not bought into on the macro level because earlier promises have not been realized. This is done necessarily to make strategies break through the waiting games in the field of OLAE visible in this scenario.

${ }^{50}$ Procurement policies can generally be used to create a demand for new products or processes, or at least to make latent consumer demands more manifest. Procurement policy can also stimulate innovation by providing an early testing ground for new products, giving firms an opportunity to experiment with different product variants free from short-term commercial pressures [22]. The UK Ministry of Defense (MoD) has had a tradition of working with procurement contract [23, 24]. Procurement policy seems to be rather more efficient in stimulating technology earlier in the product life cycle than later [25]. This seems to be the case partly because most technical advance (at least in terms of product innovation) occurs early on in the product life cycle and also partly because demand at this stage is ill-formed and poorly expressed.
}

broad promises as those of OLAE, and into open-ended support of new technological developments in general. Germany still had a tradition of government willing to push technologies for the public good, like green technologies. ${ }^{51}$ In the UK, there was already a tradition of procurement, and now also a strong interest in security. ${ }^{52}$ Thus, the Minister of Business, Innovation and Skills (BIS) initiated a debate about areas of focus for his country's future. ${ }^{53}$ The debate included leading scientists who were active in the scientific and industrial development of OLAE in UK, who were predictably optimistic. Some key industrial actors were also enthusiastic [...], but they tended to refer to Germany where companies from all over Europe were attracted $[\ldots]$ to establish manufacturing.

[During the debate, the difficulties to obtain private funding to make the transition from the research laboratory to the marketplace were emphasized. In addition, there were the further uncertainties about return on investment from unproven technologies with markets that still had to be created. To encourage marketable products and services, the Council for Science and Technology pointed to the significance of the government using procurement.]

After intensive debates with other government departments, in particular Defense, the Minister of BIS announced a plan to initiate innovative procurement mechanisms to stimulate product development and manufacturing in areas beneficial for the public interest. The actual focus of the procurement program that would start in 2011 was on security applications in e-passports. ${ }^{54}$ [The choice for this

\footnotetext{
${ }^{51}$ Governments are justified to stimulate the development of technologies with reference to public good (like sustainable and renewable energy) when there is suboptimal investment on the side of firms in the marketplace. Germany has a tradition in providing abundant R\&D resources to green technologies, especially solar energy options [26].

${ }^{52}$ See note 50 for UK MoD tradition of working with procurement contracts. In this scenario story, we take the serious security concerns for terrorism in Europe and particularly in the UK (post September 11 security concerns) as a legitimate excuse to introduce the governance mechanism of procurement to stimulate technologies related to this public good goal. ${ }^{53}$ This is a real commitment that Lord Drayson, The Minister for Science and Innovation in UK, had made at the beginning of 2009. This was an occasion for the UK government to strategically assess which S\&T areas to support. From oral evidence taken before the Innovation, Universities, Science and Skills Committee on 26 January 2009 (http://www.publications.parliament.uk/pa/cm200809/cmselect/ cmdius/50/5006.htm\#note75).

${ }^{54}$ (1) The UK government does not choose for direct governance mechanism to stimulate technology development that has potential (because they don't buy into broad promises); rather, it emphasizes the public good interest (national security), hoping that it would lead to wealth creation (it is only then that the broad promise returns). (2) EU passports planned to have digital imaging and fingerprint scan biometrics placed on a contactless chip. This combination of the biometrics aimed to create a level of security and protection against fraudulent identification papers. This was a part of measure taken under the circumstances of fighting against international terrorism (http:// www.arena.uio.no/publications/working-papers2006/papers/wp06_11.pdf; see page 7).
} 
particular strand of development had to do with the availability of a platform of relevant technological options.]

[There were also critical voices. Different advocacy groups had opposed the use of RFID technology in epassports, arguing that the failure of the technology would have drastic and irreversible consequences since privacy and identity of the holders would not be protected. The authorities, however, could justify their choice by referring to the larger good of preventing terrorism. In fact, other European countries also joined into the procurement program, which meant an expansion of development activities and firms across Europe became involved. $]^{55}$

A further effect was increased visibility for OLAE, and other application areas were identified. A company that provided a global analysis of the printed electronics area realized that, if developments of e-labels would mature, this would allow more sophisticated applications in the packaging industry. ${ }^{56}$ The example of UK buying into promises of OLAE offered an opportunity for German promise champions to push broad promises for green technologies. Politicians in Germany were interested in the move towards procurement in the UK for their own reasons. So, a meeting could be organized in 2012 in Dresden. ${ }^{57}$ [During the meeting, it was emphasized that organic photovoltaics had to be used in products as quickly as possible, even if performances were not ideal; but critics voiced concerns about the actual life expectancy, efficiency, and standardization.]

After intensive debates, the German authorities decided that the procurement route for the applications of organic photovoltaics had too many uncertainties. Instead, they identified technical reverse salients to further development, in particular encapsulation, necessary to improve life expectancy and stability issues for different application areas including lighting, displays, and photovoltaics. Actually, German industry (including lighting, automotive, photovoltaics, etc.) was already heavily involved in such developments. The

\footnotetext{
55 The emphasis on the public good justifies further work and neglect of critics. Emerging irreversibility: macro level concerns about security issues linked to the EU-wide commitment to counteract terrorism threats (post September 11 concerns) gives a strong push and enables a large initiative and expansion of technological activities in a monstrous alliance between different EU-based companies. This strategic consideration leads to the creation of a specific path/trajectory in the UK within the broad possibilities in the OLAE landscape. It is emphasized here that a strong focus is created (on displays and e-labels) due to the circumstances created in this scenario.

${ }^{56}$ Based on a multiclient study which was initiated by IDTechEx in 2009 (IDTechEx.com) engaging different industrial sectors to investigate what they have in common in their needs for e-labels and epackaging so the really high volumes can be achieved by economy of scale. Presentation and personal interaction with Dr. Peter Harrop, Chairman of IDTechEx Ltd., at a seminar where I was present (Polymer Electronics-Towards the Future, 21 April 2009, London, UK).

${ }^{57}$ The broad promises return, now in Germany and because of the visibility created by the UK move towards procurement.
}

necessary competencies were in place for a different government strategy: support for the development of a technology platform to address the reverse salient. ${ }^{58}$ Secondly, by the time that applications of organic photovoltaics had matured, the government committed itself to subsidize its use, to enhance its appeal to customers. ${ }^{59}$ The thinking behind this was clear in an interview with a high-ranking government official: "the technology platform would tie the broad promises of OLAE to specific markets to enable learning curves to advance."

The technology platform set other things in motion. By 2013, printing companies were willing to increase their investment in realizing roll-to-roll processes because they expected solutions to encapsulation issues which would reduce the uncertainty whether product manufacturing through roll-to-roll processes could be realized. ${ }^{60}$

[The expansion of activities in RFIDs and e-label systems were creating spillovers to other sectors. Retailers, packaging and printing companies, and incumbent pharmaceutical companies could launch products where RFID systems were directly printed on packages.] While expansion of activities in e-labels and RFID continued everywhere, the procurement program for e-passports ran into problems, exactly because of the reference to security as a public interest. [In 2014, a report was issued by the European Electronic Privacy Information Center revealing that the RFIDpowered flexible display technology distracted inspectors from

\footnotetext{
${ }^{58}$ Promise requirement cycle put in motion: Governance mechanism is designed and focused on stimulating the advancing of learning curves to reduce uncertainty for enactors and comparative selectors. We imply here that what is controversial is not so much the proposition that procurement policy can have an effect on innovation. The story aims to show that understanding why and when procurement can be effective. If the effect is considered, then one can think of how that effect can be maximized by an appropriately designed policy. In the case of Germany, the existence of different industrial sectors provides room to follow a different strategy: support for a technology platform that can resolve encapsulation issues (the reverse salient). The existence of the reverse salient (encapsulation issues) in the technology system of most important OLAE applications (displays, lighting, OPVs) reduces the speed of development in a variety of application fields and increases the uncertainty leading only to continuation of the waiting games. This is because without proper encapsulation films, the organic materials are very fragile. From desk research (background article in the Plastic Electronics magazine "Why the OPV industry needs to find a standard for encapsulation," volume 1, issue 4, pp. 58-62). The issue of encapsulation and lack of concrete activities to resolve it has been mentioned by all enactors interviewed in the field of OLAE in the Netherlands.

${ }^{59}$ Governance mechanism that operates on the demand side in stimulating innovation: government regulations and subsidies affecting the sale of goods by making their uptake more attractive for the users. Germany has a tradition for applying subsidies to the solar market. Although the German government was showing reservations in governmental debates in 2008, the levels of these subsidies have been reduced in 2009, but they have not been abolished. A reason to anticipate that such mechanisms of governance will be maintained in the long term in Germany.

${ }^{60}$ Breakthrough in existing waiting strategies because firms can anticipate on solutions to technical uncertainties.
} 
their duties instead of improving the effectiveness of control, actually causing more opportunity for terrorists. The increasing criticism created a dilemma in the consortium and eventually the traditional approach of checking and monitoring was restored.]

Thus, the OLAE landscape in Europe changed, and in two ways. First, photovoltaics became the dominant direction. Germany's sustained investments in organic photovoltaics had paid off in their being in the lead, and there was no specific criticism to be faced. Technology platforms which allowed niche developments for low-performance photovoltaics, supported by German government, had made considerable progress in terms of material development and standardization of cheap roll-to-roll manufacturing. ${ }^{61}$ Second, user interests from different sectors became attracted to the OLAE domain. [There was interest from other sectors (e.g., the automotive sector) to take up organic photovoltaics in their products. The technology platform also enabled exploration of niche applications in other sectors (e.g., lighting) where encapsulation was key to market introduction. But ambivalences returned when public controversy around privacy related issues in relation to the use of integrated RFID technology in e-labels emerged.]

The immediate effect was that major brand owners stopped item-level tagging and only used RFID technologies for retail purposes [xlii]. Firms shifted their focus to other applications in the trading card market where smart cards (that could be inserted into electronic reader attached to a PC) were used for entertainment purposes like online gaming. ${ }^{62}$

By 2015/2016, the OLAE landscape was very different from what it was projected to be in 2009/2010. A retired official of the UK Department BIS, who had played a key role in linking procurement philosophy and promising technologies at the time, was interviewed for a German TV production on the societal value of new technologies. Looking back, he said he would go for e-passports again, but now because this would force promise champions to become concrete, and thus, start learning processes which would actually deliver something. If not e-passports, then technology platforms that could be used

\footnotetext{
${ }^{61}$ Shift in the "innovation journey": the sudden deadlock in the epassport case and at the same time successful progress in the activities of the technology platform in Germany (on encapsulation enabling further work on important applications like OPVs) gives rise to the emergence of OPVs as the dominant OLAE option now attracting more attention due to circumstances. Move in the "innovation journey": The reduction of uncertainties about the encapsulation issues becomes a driver and enables private investment in roll-to-roll manufacturing technologies enabling more standardization work as industries become involved and coordinated efforts take shape.

62 Shift in the "innovation journey": Interests shift towards different applications and business models like the entertainment industry where smart cards are expected to be integrated in interactive/online gaming. Based on desk research. An interview with Menippos CEO Jan Thiele (a spin-off from the Technical University of Chemnitz developing printed electronic cards). He expects to see the market of gaming with smart cards to bear fruit and grow rapidly (Plastic Electronics Magazine, volume 2, issue 1).
}

for product development for other applications. The interviewer was not convinced, but had to agree that the German photovoltaics program which focused on technology platforms had delivered, even if its success depended on the active interests from the building sector.

\section{Scenario 3: initiatives along the value chain}

For reasons of space, only excerpts of the full text are given. The deleted parts are summarized (in italics) to keep the story line visible.

At a meeting of the American Institute for Research Management in 2009, Peter Hershel from Corporate Strategy of DuPont, a chemical/materials company, got into conversation with Paolo Gargini, Director of Technology Strategy at Intel, a major and innovative microelectronics company. Gargini explained how Intel had engaged with various suppliers of new generation lithography back in the 1990s because, at that time, they anticipated that they would depend on the strategies of suppliers. The new electronics, and especially OLAE, depended on materials, which had to be supplied. There was no equivalent to Intel in the OLAE domain, but Hershel realized that DuPont could be proactive: to capture value, they had to engage with technology partners further down the value chain. ${ }^{63}$

In general, chemical companies anticipate shifts in the value chain and are willing to take a long-term view even now when they feel the effects of the financial crisis. They realize that the lack of standards and unproven manufacturing technologies makes it difficult for various producers to commit to the adoption of the initial proof of concepts that were available. ${ }^{64}$ The two concerns together led DuPont to organize a top level strategy meeting in Greece in 2010, to identify ways of moving forward. A variety of relevant parties were invited, and they came, which testified to the importance they accorded to OLAE

\footnotetext{
${ }^{63}$ (1) At the time of scenario writing, material suppliers in the field of OLAE were concerned while anticipating that their business models (of selling bulk materials) could change (because of the introduction of new manufacturing technologies that are highly efficient in material usage roll). So, in terms of anticipating changes in the value chain, they became proactive. (Based on interviews with Eliav Haskal (Philips Research), Hylke Veenstra (Oce), Herman Schoo (Holst Centre), Paul Blom (University of Groningen), and Andreas Dietzel (TU Eindhoven)).

${ }^{64}$ Observed misalignment: technological uncertainty and lack of standards leading to lack of commitment at the side of users and producers, in effect leading to little or no movement in promise requirement cycles. (2) The fictive meeting at the American Institute for Research Management is introduced to show that there are recurrent patterns. Earlier in the microelectronics industry, Intel (a key and major player in terms of the value chain in microelectronics) had become proactive to initiate value chain integration. In 1996, they brought a number of suppliers together including ASML to work on next generation lithography, specifically ultraviolet lithography. Paolo Gargini has a record of being proactive, cf. his role in INC (International Nanotechnology Conference on Communication and Cooperation).
} 
and to the need to interact. The positions taken were diverse. ${ }^{65}$ [Several strategies were emphasized during the meeting, ranging from the importance of having early market requirements to exploring new markets even when performances were still not ideal and to integrate more than one function at low-cost levels to add value to new products.]

Actually, there were already some initiatives supported by the EC and actively pursued by the Plastic Electronics Foundation. The focus was on innovative companies establishing technology platforms in clusters in various locations in Europe. ${ }^{66}$ Whatever DuPont got out of the meeting in Greece, it had the effect of a seed crystal in an oversaturated solution (of promises about OLAE and industry and government actors being interested but uncertain what to do). Collaborations in the value chain became visible. Specialty chemical companies started to forge alliances with small start-ups further down the value chain to develop niche applications. ${ }^{67}$ Concurrently, several initiatives in existing technology platforms to make integrated systems were boosted as more companies realized that reaching marketable products hinged on the development of integrated systems and manufacturing processes that enabled such integration. ${ }^{68}$

What was happening is a broadening of the idea of open innovation, $[\ldots]$ to value chain interactions and clusters. Integration of different functionalities through roll-to-roll manufacturing was attempted in several regions in Europe, with support from the EU [...] and specialization occurred, as in a cluster in Scandinavia that focused on applications of RFIDs, sensors, and integrated e-labels for the packaging industry. ${ }^{69}$

\footnotetext{
${ }^{65}$ This is an attempt at anticipatory coordination located at the mesolevel.

${ }^{66}$ Based on the aims of the OPERA task force (EU-funded OPERA project led by Plastic Electronics Foundation) in the OPERA project booklet "The future of organic and large area electronics in Europe" on p. 3 lists of what needs to be done to reach the vision of OLAE in EU. ${ }^{67}$ New alignments formed along the value chain (meso-level coordination). At the time of scenario writing, intentions of material companies to take such steps were becoming materialized and indicated by strategic moves of Bayer, Solvay, AGFA Belgium, and BASF. From desk research and interviews and interaction with industry actors and analysts.

${ }^{68}$ Building critical mass as technology uncertainties are reduced: From the experience of the Holst Centre, where strategic partners still join the center as the promise of printing becomes more credible. At the time of the case research, key actors from the value chain of OLAE joined the strategic partnerships of the Holst Centre.

${ }^{69}$ The Holst Centre was envisioning and anticipating new application areas where their technology platform could show its advantage. The main reasoning behind the envisioning of potential applications was because, this way, scientist could extract technical requirements to work on, but also for communication of promises to external actors. From my interactions with Aeneas Fletterman (TNO) who was responsible for a project to visualize future applications from the R\&D activities in the Holst Centre [27]. Also, movement in promise requirement cycles: as promises become more specific and trajectories crystalize private actors also commit to the outcome.
}

By 2013, large printing companies were entering the field and started to forge alliances with material suppliers. This might lead to specialized design houses which further opened up the electronics value chain. ${ }^{70}$ By 2014 , the development of vertical integration of companies along the value chain was paying off, as companies were sharing responsibility in technology development. [...]

At the same time, actual market introduction encountered complexities. Shared responsibilities across the value chain had been productive to develop products. [But then, flexible photovoltaics that were offered to the market were rejected by a customer, which caused a legal conflict between the start-up firm and the materials company.] This attracted attention widely. Chemical suppliers, who had wanted to seize the chance of realizing the promise of their technology option quickly, now realized that, in their collaboration with SMEs, all sorts of customized requirements had to be met $[\ldots]^{71}$

The EC saw this as an opportunity to show that it could provide support where various companies had failed to collaborate sufficiently. [User laboratories were set up as an additional infrastructure where users and producers could interact more intensively.] In general, the need to find large markets is important to polymer electronics. The business strategies of various companies are geared to that. ${ }^{72}$ When

\footnotetext{
${ }^{70}$ Anticipated changes to the business model of printer manufacturers. Conventionally, the inkjet printing industry has made profits based on the sales of ink supplies, not the printers. In OLAE, material suppliers hold the IP to solution processable inks. But the actors in the printing industry anticipate shifts in the value chain when some key IP's expire to leverage economic advantage by formulating own materials or partnering with firms that have the capability to do so. (Based on an in-depth interview with Hylke Veenstra (Oce) and observations during the Seminar Tomorrows Electronics in Utrecht: Presentation Hylke Veentra of Oce.) Because of the promise of flexible manufacturing (yet to be made possible with inkjet printers and roll-to-roll manufacturing), actors in the electronics industry anticipate shifts in the electronics industry structure: Emergence of design houses where products could be custom designed and then manufactured easily. (Such shifts to the industry structure of electronics were mentioned by Herman Schoo and Andreas Dietzel in in-depth interviews.)

${ }^{71}$ Critical comparative selectors: Ambivalences of value chain integration become visible. One particular reason is because materials suppliers have chosen to collaborate with SME's which brings complexities because of customized requirements. Companies realize that collaboration and alignment to reach early niche markets also has its disadvantages.

${ }^{72}$ This is indicated by the explicit sear of the organic electronics association to identify killer applications. The term killer application has been used earlier in the computer industry to indicate the potential of a certain technology that can substantially increase sales of the platform on which it runs. This pattern is also visible in OLAE because materials suppliers have been investing huge sums of R\&D budgets to develop the materials that can be used in different applications and, if the potential applications of OLAE remain confined to niche markets, then there will be little incentives for material suppliers to keep investing in further developments. Therefore, at the time of scenario writing, there was a sense of urgency to identify potential large markets (This was also mentioned by the majority of the enactors interviewed in the field of OLAE in The Netherlands.) From desk research: Organic Electronics Association 2008.
} 
they move in that direction, the companies are confronted with the realities of the user world. ${ }^{73}$ In hindsight, it was indicative how the collaboration of the Austrian start-up Nanoident, which specialized in integrating multilayers of sensors using cheap inkjet printing, with Google Health was widely applauded, while after the actual implementation, difficulties emerged. [Health care communities had reacted negatively to the system arguing that professional quality control was absent.]

The use of sensors is not limited to medical sectors; there is also the big market of environmental monitoring which is served sometimes by the same companies. Actors in the environmental monitoring sector were afraid that the concerns about reliability of sensors would spill over into their sector. FTS, the world leader in environmental monitoring solutions, took the initiative to set up a sector-internal quality assurance program, to which other companies could subscribe. ${ }^{74}$

The events in the medical sector and in the environmental monitoring sector were followed attentively by actors in other OLAE sectors. The issues of quality control and quality assurance were now high on the agenda generally.

\section{In conclusion: further developments}

The scenarios highlighted possible developments by focusing on specific story lines. In practice, items of these story lines occur together and intermingle; this was visible occasionally. The scenarios were drawn up in 2009 for use as a platform for discussion between relevant stakeholders from the OLAE value chains (such as researchers, manufacturers,

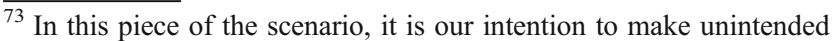
effects of moving towards large markets without seriously considering the user requirements more visible. This was essential at the time of scenario writing because, as explained in the previous point, the choice of market entry strategy in OLAE was urgent and difficult at the same time. What we want to show is that there are risk considerations, and unavoidably, there are always specificities of the contexts where technologies will be embedded. Earlier in the scenario tale, we showed the example of OPV to make risks of early market introduction without field testing on robustness visible. But that was mainly to highlight risks of business to business collaborations. Here, we use case material from sensor applications in the health care sector. We do this with the intention to show that choices for market entry strategies should seriously consider that requirements of users are met.

${ }^{74}$ This idea came from my in-depth interactions with Philippe Mattelaer (business development manager at the Holst Centre) when we were discussing the ethical, legal, and societal aspects of their sensors in health care applications. At the time we interacted in 2006 and 2007, he was already anticipating that, with generic platform technologies like wireless sensor systems that could be used in different applications, concerns about quality and robustness issues could spill over from one sector to the other. Therefore, we introduce this point to indicate measures that could be taken proactively to play safe in such situations.
}

industrial actors, government, and industrial designers). What has happened since these scenarios were constructed? We draw on two sources of information: first, what came up in two strategy articulation workshops which were held at the end of 2009; and second, interviews and attendance at meetings on OLAE by one of us (AP) in 2012. ${ }^{75}$

Strategy articulation workshops: arena for mutual learning

The two strategy articulation workshops were held in Eindhoven, the Netherlands, hosted at the Plastic Electronics Foundation, and in Heidelberg, Germany, hosted at the InnovationLab. The locations of the workshops were chosen because, at both locations, OLAE clusters were emerging, so there was also a regional interest for stakeholders to participate. Such an open-ended strategy articulation discussion was recognized as important by most of the stakeholders, and they were keen to participate. The fact that OLAE technology was still in an early stage was reflected in the mix of participants in the workshops. There was variety across types of firms and sectors, but it had been difficult to find participants from potential end users, let alone societal groups.

During the workshops, a recurrent focus was on real-world bottlenecks, but there was also broadening of the issues and strategic thinking about possible alliances. The participants considered further action in relation to the action and diagnosis as indicated in the preparatory material, including the scenarios. They recognized that elements in the scenarios were actually addressing the issues they were facing in the real world. Our diagnosis of "waiting games" occurring in the domain of OLAE was acknowledged by most of the actors involved as making explicit what they were experiencing.

The interactions in the workshops were occasions for the participants with different knowledge, experience, roles, and background to probe into each other's realities. Actually, learning occurred as a result of this type of interaction. In follow-up interviews afterwards, most participants showed their appreciation of now understanding other positions. The scenarios had prepared the ground for that in showing the variety of actors playing a role in future developments.

All in all, the workshop discussions and post-workshop evaluation validated the scenarios, both in terms of their diagnosis of the present situation and dynamics and the plausibility of the futures sketched.

\footnotetext{
${ }^{75}$ Since April 2012, Alireza Parandian works for InnovationFab in Eindhoven, which plays a key role in organizing networking and commercialization activities in the domain of OLAE in Europe. One of his tasks has been in a European Commission-funded project, Commercialization clusters of Organic and Large Area Electronics (COLAE), a project that is still running at the time of writing of this article. He has interviewed many potential users of the OLAE technologies and has been actively involved in private and public meetings in the domain.
} 
Real world developments, 2009-2012

By 2012, 3 years after the strategy articulation workshops were held, the overall situation is still the same. The scenarios outlining specific story lines remain applicable. In a sense, they are even more important because intervention initiatives which were the starting point for the scenarios are still almost absent.

The exception is that some elements of the dynamics visible in scenario 3 have become manifest. Different cluster initiatives across Europe (most strongly in Germany, UK, Finland, and The Netherlands) now cover all elements of the value chain and are supported by regional, national, and EU governments. The umbrella promise of OLAE is bringing actors together and attracts symbolic support.

There has been some progress in demand articulation through engagement with potential end users to articulate requirements, for example, through the ongoing COLAE project. Alignment of competences and activities of suitable technology partners to realize actual product development is still difficult. Breaking through the waiting games requires a strong initiative. Given what we can learn from our scenarios, procurement by a national government or a consortium of governments (scenario 2) may not be the answer, but the clustering that is continuing in Europe may enable interaction and trust building between actors along and between value chains. A serious possibility of breaking through the waiting game is that materials companies feeling threatened by backward integration of print companies, or vice versa, print companies feeling threatened by forward integration of materials companies, are willing to engage in collaboration with their new competitors. But this may well need an event, or a third party creating an occasion, to crystallize this. It would lead to a version of scenario 3 .

Another important change is the progress that has been achieved in further development of encapsulation materials, the lack of which we characterized as a reverse salient. Encapsulation is a key enabling technology for application fields in lighting and the photovoltaic sector because organic materials are highly sensitive and deteriorate when exposed to oxygen and moisture in the air [13]. Inadequate encapsulation is a critical problem in realizing organic electronics products. Recently, key research institutes like The Holst Centre in The Netherlands have announced new encapsulation methods for lighting applications [15]. At the same time, key encapsulation firms, including multinationals like $3 \mathrm{M}$ and Corning, and specialty companies, like Beneq, Vitex, and Tera Barrier Films, have all announced breakthroughs and improved encapsulation techniques that will open new opportunities [16]. Efforts are underway to test the reliability (i.e., the barrier properties) of new encapsulation techniques, important for product lifetime requirements, which are a key issue especially in the photovoltaic sector. If successful, there would be no barrier against expansion other than the uncertainties about the directions to go, given the limited articulation of user interests.
The implication is that procurement is less necessary, and the German approach to stimulate organic photovoltaics would show results faster (cf. scenario 2). The problem remains whether stimulation programs (as in Germany) create an artificial market that collapses when the stimulation is withdrawn.

Since OLAE primarily aims to substitute for silicon-based technologies and will realize new functionalities only in the longer term, there is the question whether OLAE-based products and their technologies will progress at a sufficiently rapid pace down their learning curves to overtake the incumbent technologies which also experience learning and ensuing cost reduction; this is particularly important with the silicon-based photovoltaic technologies. ${ }^{76}$ Scenario 1 addressed this issue for applications in the lighting sector. The high hopes for reducing manufacturing costs through new manufacturing processes entailed neglect of other aspects like efficiency and longevity. What we will see now, if there are signs of product development in OLAE lighting and photovoltaics, is a "battle between learning curves." This is actually a general challenge for emerging technologies. Often, the option of focusing more on new functionalities for which there is no competing technology (only lack of user demand) is highlighted in the promises, but not easy to get off the ground.

\section{Reflections}

A first round conclusion is that the scenarios remained relevant, not just because the situation did not change very much, but also because what did happen fitted the thrust of the scenarios. This speaks to the value of a methodology building on longer-term dynamics and endogenous futures. In constructing such scenarios, a trade-off must be made between embracing actual complexity and reducing it by highlighting key issues and dilemmas. Our guideline here has been to anticipate actor strategies and interactions in relation to possible developments in the domain of OLAE, as such and to support and enlighten the different actors involved in their articulation of strategies. ${ }^{77}$ While our results speak to the future of OLAE, the methodology is applicable to all domains of emerging technologies with their combination of novelty and uncertainty.

These considerations lead to a final reflection about futures research. The business of future researchers is to construct

\footnotetext{
${ }^{76}$ Christoph Brabec, one of the leading scientists in the field of organic photovoltaics warned about the unexpected price reduction of siliconbased photovoltaic technologies. (Presentation: Lifetime of Organic Solar Cells-Is Grid Connected Operation Realistic? SEMICON Europe Conference, Dresden, Germany, 10-12 October 2012).

${ }^{77}$ Our focus was on strategy articulation workshops with different types of actors, functioning as a microcosmos, but the approach is not limited to these workshops. One can envisage constructing such scenarios for industry or government or other actors up to NGOs. In fact, some participants in our workshops from industry asked us for permission to use our scenarios for internal strategy discussion in their firm.
} 
futures, but we positioned such constructing of futures in relation to anticipation and strategy articulation by various actors - de facto futurists. Future researchers thus contribute to distributed strategic intelligence about emerging technologies [17]. They add to it, as we have done for the domain of OLAE, but they can also introduce further reflection.

In our diagnosis, and the subsequent structuring of the scenarios as starting with one or another intervention to break through the waiting games, we could be seen as wanting to help overcome the waiting games, and as effectively as possible. We did introduce complexities by showing that such interventions will have repercussions and side effects which will make them less effective on their own terms, even while there might well be unexpected positive effects as well. What we did not consider is that there may well be a positive side to a waiting game situation, as it creates a breathing space for reflection about what is important, rather than just going with the sense of urgency in running after promises. ${ }^{78}$ We could have created a fourth scenario where the intervention was not about realizing OLAE as soon as possible, but about discussing the value of realizing OLAE. Such discussions do occur for other emerging technologies, for example, synthetic biology, and vignettes (mini-scenarios) about future developments are used to inform the discussion. The vignettes are now produced by ethicists, without the quality control that future researchers can offer. The important point, however, is that contributions to strategic intelligence about emerging technologies should include a reflexive component. This is a further challenge for future research.

Open Access This article is distributed under the terms of the Creative Commons Attribution License which permits any use, distribution, and reproduction in any medium, provided the original author(s) and the source are credited.

\section{References}

1. Parandian A, Rip A, Te Kulve H (2012) Dual dynamics of promises and waiting games around emerging nanotechnologies. Tech Anal Strat Manag 24(6):565-582

2. Robinson DKR (2009) Co-evolutionary scenarios: an application to prospecting futures of the responsible development of nanotechnology. Technol Forecast Soc Chang 76:1222-1239

3. Parandian A (2012) Constructive TA of newly emerging technologies. Stimulating learning by anticipation through bridging events. Dissertation, Delft University of Technology

4. Rip A, Te Kulve H (2008) Constructive technology assessment and sociotechnical scenarios. In: Fisher E, Selin C, Wetmore JM (eds) The yearbook of nanotechnology in society, volume I: presenting futures. Springer, Berlin, pp 49-70

5. Abbott A (1992) From causes to events. Notes on narrative positivism. Sociol Methods Res 20(4):428-455

\footnotetext{
${ }_{78}$ In their critical analysis of innovation patterns geared to technoscientific promises, Joly et al. [28] suggested "slow innovation" as an alternative.
}

6. Shirakawa H, Louis EJ, MacDiarmid AG, Chiang CK, Heeger AJ (1977) Synthesis of electrically conducting organic polymers: halogen derivatives of poly-acetylene, (CH)x. J Chem Soc Chem Commun (16):578-580

7. Shaw JM, Seidler PF (2001) Organic electronics: introduction. IBM J Res Dev 45:1-5

8. Sauer A et al (2002) Collection of state-of-the-art in the area of polytronics. Deliverable D1.1a POLYSCENE IST-2001-37412, see p. 30. Available at http://cordis.europa.eu

9. Sheats JR (2004) Manufacturing and commercialization issues in organic electronics. J Mater Res 19:1974-1989

10. Gamota DR, Brazis P, Kalyanasundaram K, Zhang J (eds) (2004) Printed organic and molecular electronics. Kluwer Academic, Norwell

11. Kelley TW, Baude PF, Gerlach C, Ender DE, Muyres D, Haase MA, Vogel DE, Theiss SD (2004) Recent progress in organic electronics: materials, devices, and processes. Chem Mater 16:4413-4442

12. Cleland TA (2003) Printed electronics: the next inkjet revolution? Master's dissertation, Sloan School of Management at MIT, see p. 108

13. Patterson P (2009) Beyond the beaker, how to achieve successful market adoption for emerging technologies. Kohritsu, Beaverton, pp 160-163

14. King Z (2008) Plastic electronics in the UK; lack of end-users is likely to constrain access to markets for UK SMEs. Available at http://www.printedelectronics.net/PlasticElectronicsintheUK.htm\#1

15. Blom P, Van Mol T (2012) LEDs are on a roll. Available at http:// mag.digitalpc.co.uk/Olive/ODE/physicsworld/. Accessed December 2012

16. NanoMarkets Report (2012) Markets and materials for thin film and organic PV encapsulation-2012

17. Kuhlmann S, Boekholt P, Georghiou L, Guy K, Héraud J-A, Laredo P, Lemola T, Loveridge D, Luukkonen T, Polt W, Rip A, SanzMenendes L, Smits R (1999) Improving distributed intelligence in complex innovation systems. Final report to the European Union of the TSERP Network on Advanced Science and Technology Policy Planning, Fraunhofer Institut für System- und Innovationsforschung, Karlsruhe, June 1999. Available at http://mpra.ub.uni-muenchen.de/ 6426/1/Final.pdf

18. Hughes TP (1983) Networks of power: electrification in Western society, 1880-1930. The John Hopkins University Press, Baltimore

19. European Commission (2008) Organic and large area electronics project portfolio: sixth and seventh research and development framework programmes. EU Commission: DG Information Society and Media. Available at ftp://ftp.cordis.europa.eu/pub/fp7/ ict/docs/organic-elec-visual-display/olae-project-portfolio_en.pdf

20. Strategic Research Agenda (2009) Towards green electronics. Strategic research agenda organic and large area electronics. Available at http:// opera-project.eu/uploads/OLAE\%20SRA\%20FINAL\%20VS\%204\% 2091509.pdf

21. Organic Electronics Association (2008) OE-A roadmap for organic and printed electronics (May 2008 version). White paper, German Engineering Federation (VDMA). Available at http://www.novaled.com/ downloadcenter/oe-a_roadmap_white_paper_2008_may_public.pdf

22. Geroski PA (1990) Procurement policy as a tool of industrial policy. Int Rev Appl Econ 4(2):182-198

23. McKinsey and Company (1988) Strengthening competitiveness in UK electronics. National Economic Development Office, London

24. NEDO (1982) Industrial policy in the UK. National Economic Development Office, London

25. Rothwell R, Zegveld W (1981) Industrial innovation and public policy. Frances Pinter Ltd., London

26. Wüstenhagen R, Bilharz M (2006) Green energy market development in Germany: effective public policy and emerging customer demand. Energy Policy 34(13):1681-1696

27. Fletterman A (2007) Roads into the future, 1st edn. Holst Centre, Eindhoven

28. Joly P-B, Rip A, Callon M (2010) Reinventing innovation. In: Arentsen M, van Rossum W, Steenge B (eds) Governance of innovation. Edward Elgar, Cheltenham, pp 19-32 